\title{
JOURNAL.RU
}

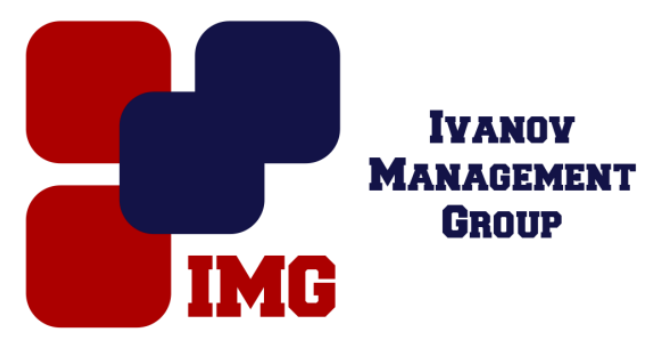

Лебеденко А.А., Тараканова Т.Д., Семерник О.Е., Тюрина Е.Б. Ростовский государственный медицинский университет Ростов-на-Дону, Россия

doi: $10.18411 / 1 \mathrm{j}-31-05-2017-37$

idsp 000001:1j-31-05-2017-37

\section{Эхокардиографические признаки кардиальных изменений у детей с бронхиальной астмой}

Бронхиальную астму (БА) принято считать болезнью преимущественно одной системы, однако, тесная анатомическая и функциональная взаимосвязь систем кровообращения и дыхания обуславливает изменения в каждой из них уже на ранних стадиях поражения другой[1, 2]. В патогенезе развития бронхиальной обструкции при обострении заболевания значительную роль играет состояние центрального и периферического отделов вегетативной нервной системы, но в то же время их функция чрезвычайно важна и в обеспечении процессов адаптации дыхательной и сердечно-сосудистой систем (CСC) ребенка с БА [3, 4]. Гипоксемия, развивающаяся при бронхообструкции, приводит к вазоконстрикции, запуская тем самым процессы ремоделирования сосудов в легких, впоследствии обуславливающего рост давления в легочных сосудах, легочной артерии (ЛА), а соответственно и в правых отделах сердца. Длительное негативное воздействие на правые отделы сердца постепенно вызывает развитие дисфункции правого желудочка (ПЖ), которая значительное время может не иметь клинических проявлений, а манифестировать лишь при декомпенсации сократительной функции миокарда.Значительное влияние на изменение морфометрической структуры сердечной мышцы оказывают нейрогуморальные факторы, запускающие процессы ремоделирования не только в сосудах, но и в миокарде левого желудочка $[5,6,7]$. Поэтому столь важно проводить исследование строения сердечно-сосудистой системы пациентов с БА на самых ранних этапах развития заболевания. 
Цель работы: изучить морфометрические особенности структуры правых и левых отделов сердца у детей с бронхиальной астмой.

Материалы и методы. Проведено одномоментное обследование 60 детей в периоде обострения БА, из них 41 мальчик (68,3\%) и 19 девочек $(31,7 \%)$. Обследуемые были разделены на 2 группы: в 1-ю группу включены 30 пациентов в возрасте от 5 до 11 лет, 2-ю группу составили 30 подростков (от 12 до 17 лет). Легкая интермиттирующая астма отмечена у 44 (73,0\%) больных, легкая персистирующая у 9 (15,3\%) пациентов и среднетяжелая - у $7(11,7 \%)$ обследуемых. Степень тяжести оценивали согласно Национальной программе «Бронхиальная астма у детей. Стратегия лечения и профилактика» (2014) [8]. Контрольную группу составили 40 человек, сопоставимых по полу и возрасту.

Всем детям проведено комплексное клинико-лабораторное и инструментальное обследование.ЭхоКГ проводили на сканере VIVID-3 (General Electric, США) с использованием трансторакального матричного датчика 3,5 МГц в положении больного лежа на спине или на левом боку по стандартной методике. Морфометрические параметры правых и левых отделов сердца оценивались в двухмерном В- и одномерном М-режимах. Проводилось измерение следующих показателей: конечно-диастолического (КДР) и конечносистолического (КСР) диаметров левого желудочка (ЛЖ), толщины межжелудочковой перегородки (МЖП) и задней стенки ЛЖ в диастолу (ЗСЛЖ), диаметра правого желудочка (ПЖ), левого предсердия (ЛП), восходящей аорты (Ао) и ствола легочной артерии (ЛА). Для оценки систолической функции определяли ударный объем (УО) ЛЖ по формуле: КДО-КСО (в мЛ); минутный объем кровотока (МОК) по формуле: МОК=УОхЧСС (в л/мин), а также рассчитывали фракцию выброса (ФВ) и фракцию укорочения (ФУ) ЛЖ по формулам Тейхольца.

Полученные данные обработаны с помощью программы Statistica 7.0. При нормальном распределении достоверность различий вычисляли по критерию Стьюдента $(\mathrm{p}<0,05)$, в остальных случаях использовали непараметрический метод Манна-Уитни.

Результаты. Проведенный сравнительный анализ полученных морфометрических показателей, представленных в таблице 1, не выявил существенных отличий у пациентов с БА и детей контрольной группы, что подтверждает сведения о более позднем развитии морфологических изменений миокарда, формирующихся у больных $\mathrm{c}$ хронической бронхолегочной патологией. 
Таблица 1 Морфометрические показатели сердия и сосудов у паџиентов с бронхиальной астмой и детей

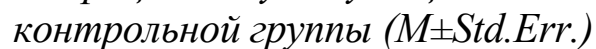

\begin{tabular}{|c|c|c|c|c|c|c|}
\hline Показатели & $\begin{array}{c}\text { Пациенты с БА } \\
\text { 6-11 лет }\end{array}$ & $\begin{array}{c}\text { Контроль- } \\
\text { ная группа } \\
\text { 6-11 лет }\end{array}$ & P & $\begin{array}{c}\text { Пациенты с } \\
\text { БА } \\
12-18 \text { лет }\end{array}$ & $\begin{array}{c}\text { Контроль- } \\
\text { ная группа } \\
12-18 \text { лет }\end{array}$ & P \\
\hline Ао, см & $1,47 \pm 0,03$ & $1,49 \pm 0,04$ & 0,679 & $1,82 \pm 0,04$ & $1,78 \pm 0,04$ & 0,489 \\
\hline ЛП, см & $1,97 \pm 0,05$ & $1,99 \pm 0,08$ & 0,889 & $2,30 \pm 0,06$ & $2,37 \pm 0,09$ & 0,538 \\
\hline ПЖ, см & $2,00 \pm 0,05$ & $1,94 \pm 0,06$ & 0,494 & $2,32 \pm 0,05$ & $2,28 \pm 0,07$ & 0,585 \\
\hline МЖП, см & $0,69 \pm 0,02$ & $0,66 \pm 0,02$ & 0,270 & $0,75 \pm 0,02$ & $0,79 \pm 0,02$ & 0,205 \\
\hline КДР, см & $3,82 \pm 0,12$ & $3,75 \pm 0,09$ & 0,669 & $4,54 \pm 0,11$ & $4,29 \pm 0,10$ & 0,108 \\
\hline ЗСЛЖ, см & $0,71 \pm 0,02$ & $0,69 \pm 0,02$ & 0,366 & $0,76 \pm 0,02$ & $0,81 \pm 0,03$ & 0,164 \\
\hline КСР, см & $2,21 \pm 0,08$ & $2,27 \pm 0,06$ & 0,615 & $2,91 \pm 0,08$ & $2,63 \pm 0,09$ & 0,022 \\
\hline ЛА, см & $1,47 \pm 0,03$ & $1,47 \pm 0,05$ & 0,974 & $1,80 \pm 0,05$ & $1,75 \pm 0,05$ & 0,467 \\
\hline Брюшная Ао, см & $1,08 \pm 0,02$ & $1,12 \pm 0,03$ & 0,284 & $1,39 \pm 0,04$ & $1,35 \pm 0,02$ & 0,428 \\
\hline
\end{tabular}

Однако необходимо отметить, что выявлена тенденция к увеличению размеров ПЖ у всех обследованных больных в сравнении со здоровыми пациентами. Структурные изменения миокарда ПЖ являются ранними признаками ремоделирования сердечной мышцы, возникающими на фоне значительного повышения давления в малом круге кровообращения в периоде обострения заболевания. В ряде случаев расширение правых отделов сердца может сопровождаться дилатацией ствола (более 3,00 см) и ветвей ЛА, но проведенные нами эхокардиографические исследования не выявили существенных отличий у пациентов с БА и у детей контрольной группы $(p=0,467)$, при этом максимальные значения диаметра устья ЛА не превышали $1,85 \mathrm{~cm}$.

При анализе планиметрических параметров левых отделов сердца (ЛП, ЗСЛЖ, КСР, КДР) достоверно значимых отличий в группах обследованных пациентов не отмечалось ( $>>0,05)$. Полученные данные свидетельствуют о том, что левые отделы сердца у пациентов с БА менее часто подвергаются структурным изменениям, тем не менее, неконтролируемое течение заболевания может привести к формированию кардиальных изменений. Это подтверждается тем, что у подростков с БА отмечено достоверно значимое увеличение КСР, по сравнению с контрольной группой $(\mathrm{p}=0,022)$. Поэтому столь важно правильно подобрать бронхолитическую терапию, но и вовремя назначить противовоспалительные препараты $[9,10,11]$, чтобы предотвратить развитие осложнений в будущем.

Заключение. Выявленные морфометрические особенности строения правых и левых отделов сердца позволяют трактовать их как предпосылки к ремоделированию миокарда у детей с БА. Своевременная диагностика данных нарушений позволяет на ранних этапах провести правильную коррекцию 
назначенной терапии для предотвращения формирования «легочного» сердца у детей в будущем, уменьшив тем самым риск развития сердечной недостаточности.

1. Кадымов Н.В. Клинико-ультразвуковая характеристика сердечно-сосудистой системы при бронхиальной астме у детей: Автореф. дисс. канд. мед. наук. - М., 2009. - 16 с.

2. Лебеденко А.А., Тараканова Т.Д., Семерник О.Е. Состояние систолической и диастолической функции сердца у подростков с бронхиальной астмой в периоде обострения// Медицинский вестник Северного Кавказа.- 2015.- Т. 10, № 3.- С. 217 221.

3. Лебеденко А.А., Тараканова Т.Д., Козырева Т.Б. и др.Спектральный анализ вариабельности сердечного ритма - новый взгляд на проблему вегетативной дисфункцииу детей с бронхиальной астмой // Медицинский вестник Юга России. 2013. № 1. C. $37-41$.

4. Семерник О.Е., Лебеденко А.А. Особенности вегетативного реагирования у детей с бронхиальной астмой в периоде обострения заболевания // Вестник Российской академии медицинских наук. - 2015. - Т. 70. № 2. - С. 222-226.

5. Лебеденко А.А., Семерник О.Е. Нейрогуморальные аспекты обострения бронхиальной астмы у детей // Пульмонология. 2013. № 5. С. 36-39.

6. Лебеденко А.А., Семерник О.Е., Тараканова Т.Д., Козырева Т.Б., Касьян М.С., Носова Е.В. Нейрогуморальные изменения в периоде обострения бронхиальной астмы у детей // Цитокины и воспаление. -2014.- Т. 13. № 3.- С. 113-114.

7. Семерник О.Е., Тараканова Т.Д., Лебеденко А.А. Кардиогемодинамические предпосылки ремоделирования миокарда у детей с бронхиальной астмой // Валеология. 2013. № 1. С. 48-54.

8. Национальная программа «Бронхиальная астма у детей. Стратегия лечения и профилактика». 4-е изд., перераб. и доп. М.: Оригинал-макет; 2014. - 184 с.

9. Лебеденко А.А. Клинико-фармакоэпидемиологический мониторинг и прогнозирование течения бронхиальной астмы у детей // автореферат диссертации на соискание ученой степени доктора медицинских наук / Ростовский государственный медицинский университет. Ростов-на-Дону, 2012.

10. Лебеденко А.А., Семерник О.Е. Оптимизация бронхолитической терапии у детей с обострением бронхиальной астмы с учетом риска развития кардиогемодинамических нарушений // Экспериментальная и клиническая фармакология. - 2015. - Т. 78. - № 7. C. 7-11. 